Sumadi $\cdot$ D. Sobardini $\cdot$ P. Suyatmana $\cdot$ M. Rachmadi $\cdot$ E. Suminar

\title{
Peningkatan produktivitas tanaman kedelai kultivar Anjasmoro asal benih terdeteriorasi dengan kompos Trichoderma dan bokashi
}

\section{Productivity increased of soybean cv Anjasmoro coated with Trichoderma compost and accompanied by bokashi compost}

Diterima : 10 September 2018/Disetujui : 13 Desember 2018 / Dipublikasikan : 31 Desember 2018 CDepartment of Crop Science, Padjadjaran University

\begin{abstract}
Trichoderma spp is a group of antipatogenic fungi, especially seedling wilted, while bokashi is a compost enriched with some microbes that are beneficial to plant growth. This paper is a compilation of pot experiment using Trichoderma compost for coating deteriorated seed and accompanied by bokashi on dry land soil and paddy soil in 2014 and 2017 respectively. The first experiment compares the effectiveness of several biological agents as a seed coating of its effect on seed vigor and yield. The results of first experiment showed that the use of $2 \mathrm{~g}$ Trichoderma compost 100 seeds $^{-1}$ was better than other biological agents. However between 1.2 and $3 \mathrm{~g}$ of Trichoderma compost per 100 seeds was not significant effect on seed vigor and yield. The results of experiment showed that the coating of seeds with $1-3 \mathrm{~g}$ of Trichoderma spp compost 100 compared with pesticide seed coatings. Increased of yield only affected bokashi application. Application of bokashi $15 \mathrm{t}$ ha $^{-1}$ abble to produce $19.83 \mathrm{~g}$ seed per plant or equivalent to $2.379 \mathrm{t} \mathrm{ha}^{-1}$ or $27.3 \%$ higher than the control.
\end{abstract}

Key words: Deteriorated seeds · Seed coating • Trichoderma $\cdot$ Bokashi

Sari Trichoderma spp merupakan golongan fungi yang bersifat antipatogen, khususnya layu kecambah, sedangkan bokashi merupakan kompos yang diperkaya dengan beberapa mikroba yang bermanfaat bagi pertumbuhan tanaman.Tulisan ini merupakan rangkuman penelitian pot menggunakan kompos Trichoderma spp sebagai pelapis benih terdeteriorasi

Dikomunikasikan oleh Yuyun Yuwariah

Sumadi, D. Sobardini $\cdot$ P. Suyatmana $\cdot$ M. Rachmadi $\cdot$ E.

Suminar

Staf pengajar Program Studi Agroteknologi Faperta Unpad

Korespondensi: sumadi@unpad.ac.id disertai bokashi kotoran hewan yang dilakukan pada tanah lahan kering dan tanah sawah pada tahun 2014 dan 2017. Percobaan pertama membandingkan efektivitas beberapa agen hayati sebagai pelapis benih pengaruhnya terhadap vigor benih dan hasil tanaman. Hasil percobaan menunjukkan penggunaan kompos Trichoderma hasilnya lebih baik dibandingkan agen hayati lainnya. Hasil percobaan selanjutnya menunjukkan bahwa pelapisan benih dengan 1 sampai $3 \mathrm{~g}$ kompos Trichoderma spp per 100 butir benih pengaruhnya tidak nyata dibandingkan dengan penggunaan pelapis benih berupa pestisida, baik terhadap vigor maupun hasil biji per tanaman. Pemberian bokashi sebaliknya secara nyata mampu meningkatkan hasil biji per tanaman. Pemberian bokashi $15 \mathrm{t} \mathrm{ha}^{-1}$ menghasilkan biji seberat 19.83 g per tanaman atau setara dengan 2,379 $\mathrm{t} \mathrm{ha}^{-1}$ atau $27,3 \%$ lebih tinggi dari kontrol.

Kata kunci : Benih terdeteriorasi · Pelapisan benih $\cdot$ Trichoderma $\cdot$ Bokashi

\section{Pendahuluan}

Kedelai (Glycine $\max$ (L.) Merr) merupakan komoditas pangan penting setelah padi dan jagung. Kandungan proteinnya cukup tinggi rata-rata mencapai $37-43 \%$, lemak $\pm 18 \%$ (Ginting dkk., 2009), sehingga kedelai merupakan bahan baku potensial untuk produk olahan, baik skala industri rumah tangga maupun untuk industri pangan dan pakan. Kebutuhan akan kedelai terus meningkat sejalan dengan pertambahan penduduk, berkembangannya industri pakan ternak dan pemahaman akan nilai gizi yang dikandungnya.

Walaupun demikian, peningkatan kebutuhan belum mampu diimbangi dengan produksi 
dalam negeri, sehingga dilakukan impor. Peningkatan produksi terus diupayakan untuk pemenuhan kebutuhan dalam negeri, sehingga dapat mengurangi impor. Penggunaan benih unggul berkualitas tinggi disertai aplikasi teknik budidaya tanaman secara utuh merupakan salah satu upaya peningkatan produksi. Selain itu, juga perlu dilakukan pengendalian organisme pengganggu tanaman sedini mungkin, karena hama dan penyakit tanaman kedelai sudah ditemukan sejak fase kecambah sampai fase perkembangan biji (Marwoto dkk., 2006).

Salah satu upaya mengatasi masalah tersebut adalah perbaikan vigor bibit dengan pelapisan benih. Pelapisan benih atau seed coating yaitu melapisi benih dengan suatu bahan kimia berupa pestisida ataupun nutrisi tanpa merubah bentuk benih (Copeland dan McDonald, 2004). Suspensi biakan murni mikroba pun dapat digunakan sebagai pelapis benih, sehingga dikenal dengan istilah biological seed treatment (Copeland dan McDonald, 2004) atau perlakuan benih secara hayati (Agustiansyah, dkk., 2010; Ilyas, 2012). Perlakuan benih dapat berupa biakan murni Rhizobium spp maupun tanah bekas pertanaman kedelai, sehingga produktivitas tanaman meningkat (Adisarwanto dan Wudianto, 1999). Selain Rhizobium spp, bakteri lain yang dapat digunakan adalah bakteri penambat $\mathrm{N}$ lain yaitu Azotobacter. Kelebihan Azotobacter spp yaitu mampu memperbaiki perakaran tanaman sehingga meningkatkan kemampuan menyerap unsur hara (Rodelas et. al., 1999).

Selain kedua agen hayati tersebut dapat juga digunakan fungi yang bersifat antipatogen tular tanah yaitu Trichoderma spp (Harmann et al., 2004). Bahkan Trichoderma spp yang diaplikasikan pada tanah dapat memacu pertumbuhan tanaman, memacu perkecambahan dan meningkatkan vigor bibit padi (Harmann, 2006). Walaupun demikian, dampaknya terhadap hasil tanaman tidak konsisten. Pada percobaan pot menggunakan tanah lahan kering, tanaman asal benih yang dilapisi kompos Trichoderma menghasilkan biji paling tinggi dibandingkan perlakuan lainnya (Sumadi, dkk., 2014). Berbeda halnya pada saat ditanam di lapangan, hasil kedelai asal benih yang dilapisi kompos Trichoderma dosis $1 \mathrm{~g} / 100$ butir biji tidak berbeda nyata dengan pelapisan $2 \mathrm{~g}$ dan $3 \mathrm{~g} / 100$ butir biji maupun dengan kontrol (Sumadi, dkk., 2015).

Percobaan lain yang dilakukan Sumadi dkk (2011) menunjukkan bahwa pelapisan benih kedelai dengan insektisida thimetoksam pada dosis anjuran berpengaruh baik terhadap viabilitas, vigor benih dan bibit, serta pertumbuhan awal, namun tidak berpengaruh nyata terhadap hasil tanaman. Berbeda halnya jika disertai dengan pemberian bokashi, pengaruhnya tidak saja pada tumbuh vegetatif awal tetapi sampai pada fase pengisian biji. Pelapisan benih dengan insektisida thiametok-sam $2 \mathrm{ml} \mathrm{kg}^{-1}$ disertai penambahan bokashi $15 \mathrm{t} \mathrm{ha}^{-1}$ mampu menurunkan serangan hama lalat bibit serta meningkatkan jumlah bintil akar efektif, pertumbuhan, komponen hasil, dan hasil tanaman kedelai (Sumadi, dkk., 2013). Apabila dosisnya ditingkatkan pengaruhnya tidak berbeda nyata dengan dosis yang lebih rendah (Rahman, dkk., 2014).

Tujuan dari penelitian ini adalah untuk menetapkan keefektifan jenis agen hayati, dosis kompos Trichoderma sebagai pelapis benih dan dosis bokashi yang pengaruhnya paling baik terhadap vigor bibit dan hasil tanaman. Keefektifan kompos Trichoderma sebagai pelapis benih untuk meningkatkan hasil kedelai bergantung pada dosis bokashi yang diberikan.

\section{Bahan dan Metode}

Dua tahap percobaan pot dilaksanakan di tempat terbuka kebun percobaan Fakultas Pertanian Unpad, kampus Jatinangor, dengan ketinggian $\pm 700 \mathrm{~m} \mathrm{dpl}$, masing-masing dilaksanakan pada bulan April - Juli 2014 dan April - Juli 2017. Media tanam yang digunakan masing-masing berupa tanah lahan kering dan tanah sawah yang dikeringkan. Percobaan pertama menguji kefektifan beberapa agen hayati untuk pelapis benih, selanjutnya percobaan kedua menguji dosis kompos Trichoderma spp dan bokashi.

Bahan-bahan yang digunakan meliputi benih kedelai varietas Anjarmoro terdeteriorasi (Daya Berkecambah 74-80 \%) koleksi Laboratorium Teknologi Benih, Fakultas Pertanian Unpad, insektisida thiametoksam, inokulan Rhizobium spp., inokulan Azotobacter spp., kompos Trichoderma, dan bokashi kotoran sapi. Bahan-bahan lainnya berupa satu paket pupuk, pestisida (insektisida, fungisida dan herbisida), kertas merang, kantong plastik, polybag hitam, mulsa plastik hitam perak (MPHP), dll. Alat-alat yang digunakan meliputi thermohigrometer, timbangan elektrik, oven elektrik, germinator, alat-alat pengolahan tanah, dll. 
Percobaan pertama dan kedua dirancang dengan Rancangan Petak Terbagi dua faktor masing-masing diulang tiga kali. Percobaan pertama menguji interaksi dua tingkat vigor benih dan lima macam pelapis benih (tanpa pelapis benih, thiametoksam, Rhizobium, Azotobacter, gabungan Rhizobium dan Azotobacter, serta kompos Trichoderma).

Rancangan perlakuan percobaan kedua terdiri dari dosis bokashi dan dosis kompos tricho. Tiga dosis kompos bokashi terdiri dari $b_{0}$ $=0 \mathrm{tha}^{-1}, \mathrm{~b}_{1}=7.5 \mathrm{tha}^{-1}\left(300 \mathrm{~g} \mathrm{pot}^{-1}\right)$, dan $\mathrm{b}_{2}=15 \mathrm{t}$ ha $^{-1}$ (600 $\left.\mathrm{g} \mathrm{pot}^{-1}\right)$. Faktor kedua adalah dosis pelapis benih hayati (C) yaitu $\mathrm{c}_{0}=$ tanpa pelapis benih, $\mathrm{c}_{1}=$ thiametoxam (dosis rekomendasi), $\mathrm{c}_{2}$ $=1 \mathrm{~g}$ per 100 butir biji $\left(2.5 \mathrm{~kg} \mathrm{ha}^{-1}\right.$ kompos Trichoderma) , $\mathrm{c}_{3}=2 \mathrm{~g}$ per 100 butir biji ( $5 \mathrm{~kg} \mathrm{ha}^{-}$ ${ }^{1}$ kompos Trichoderma dan $c_{4}=3$ g per 100 butir biji (7.5 kg ha-1 Kompos Trichoderma).

Pemberian pelapis benih dilakukan dengan cara mencampur benih di dalam kantong plastik ukuran $100 \mathrm{~g}$. Setelah itu dilakukan penanaman benih pada media yang sudah disiapkan. Setiap lubang tanam ditanami 3 butir benih. Bersamaan dengan penanaman dilakukan pula pemupukan, masing-masing $1 \mathrm{~g}$ Urea, SP 36, dan $\mathrm{KCl}$ di kanan kiri lubang tanam.

Satu minggu setelah penanaman dilakukan pengamatan perkecambahan pada setiap polybag. Pada umur 2 minggu setelah tanam (mst) dilakukan penjarangan bibit sekaligus panen destruktif untuk keperluan analisis vigor bibit. Pemeliharaan tanaman dilakukan sejak tanam sampai menjelang panen, meliputi penyiraman, pencabutan gulma yang ada sekitar tanaman, serta pengendalian hama dan penyakit. Pada umur 85 hst dilakukan pemanenan dilanjutkan dengan pengolahan benih mulai penjemuran brangkasan, penghitungan polong, pemipilan, pengeringan biji, penghitungan biji, dan penimbangan bobot biji selama 3 minggu. Untuk keperluan data mutu fisiologis benih dilakukan uji viabilitas dan vigor benih.

Parameter yang diamati meliputi vigor bibit, komponen hasil, dan hasil biji per tanaman. Parameter diuji dengan uji $\mathrm{F}$ taraf nyata $5 \%$, selanjutnya untuk mengetahui perbedaan antar perlakuan dilakukan uji BNT.

\section{Hasil dan Pembahasan}

Kondisi lingkungan tumbuh. Kondisi cuaca dan kesuburan tanah masih pada batas optimal bagi pertumbuhan tanaman kedelai. Rata-rata suhu maksimum selama percobaan dari bulan April Juli antara $28,1-28,8^{\circ} \mathrm{C}$ dan suhu minimum ratarata antara $12,2-13,6{ }^{\circ} \mathrm{C}$, curah hujan 1,8-6,6 mm per bulan, kelembabaan udara pada siang hari \pm 65 $\%$, dan penyinaran sinar matahari 58,75-75 \%. Kemasaman tanah termasuk kriteria agak masam, $\mathrm{C}$ organik sedang, $\mathrm{C} / \mathrm{N}$ sedang, $\mathrm{P}_{2} \mathrm{O}_{5}$ sangat tinggi, $\mathrm{N}$ rendah, $\mathrm{K}_{2} \mathrm{O}$ sangat tinggi, dan tekstur lempung liat berdebu (Departemen ITSL, Faperta Unpad, 2017).

Hasil analisis tanah lahan kering sebelum percobaan hanya bakteri Azotobacter sp yang ditemukan, yaitu sebanyak 3,34 x $10^{8} \mathrm{cfu} / \mathrm{g}$. Hal ini berarti keberadaan Azotobacter sp pada media percobaan sudah cukup banyak. Hal yang berbeda dengan Rhizobium sp dan Trichoderma sp yang tidak terdeteksi. Adapun populasi Rhizobium spp dan Trichoderma spp tanah sawah sebelum percobaan masing-masing $1,9 \times 10^{7}$ dan $2,00 \times 10^{3} \mathrm{~g} / \mathrm{CFU}$. Hal ini membuktikan bahwa pada tanah sawah pun terdapat komunitas mikroba yang keberadaannya dipengaruhi kondisi lingkungan dan pengelolaan tanah (Prihastuti dan Sudaryono, 2008). Hal ini diduga adanya proses migrasi mikroba melalui aliran air dari lahan-lahan sekitar sawah yang sering dijadikan tempat penanaman kedelai (Komunikasi Pribadi, 2017).

Vigor Kecambah. Berdasarkan analisis statistik disimpulkan pengaruh tingkat vigor benih terhadap vigor kecambah dan jumlah nodula efektif tidak bergantung pada jenis pelapis benih (Tabel 1). Vigor bibit sebagaimana terukur dengan daya tumbuh dan bobot kering kecambah kualitas asal benih dan pemberian pelapis benih pengaruhnya tidak berbeda nyata. Jika dibandingkan dengan kualitas awal benih (Daya Berkecambah $84 \%$ dan $75 \%$ ), masingmasing mengalami penurunan. Daya tumbuh benih terdeteriorasi di lapangan lebih rendah dibandingkan hasil uji di laboratorium, daya tumbuhnya mengalami penurunan. Pemberian pelapis benih tidak serta merta mampu meningkatkan vigor tanaman. Pemberian pelapis benih hanya berpengaruh terhadap jumlah nodula efektif. Rhizobium, Azotobacter, maupun campuran keduanya, mampu meningkatkan jumlah nodula efektif lebih banyak dibandingkan dengan pelapis benih berupa Thiametoksam dan kompos Trichoderma spp.

Demikian pula halnya dengan pemberian pelapis benih berbagai dosis kompos Trichoderma spp. dan bokashi tidak berpengaruh nyata 
terhadap daya tumbuh dan bobot kering kecambah, tetapi berpengaruh nyata terhadap tinggi kecambah 2 mst (Tabel 2).

Tabel 1. Daya tumbuh benih, bobot kering kecambah, jumlah nodula efektif.

\begin{tabular}{|c|c|c|c|}
\hline Perlakuan & $\begin{array}{c}\text { Daya } \\
\text { Tumbuh } \\
(\%)\end{array}$ & $\begin{array}{l}\text { Bobot } \\
\text { Kering } \\
\text { Kecam- } \\
\text { bah }(\mathrm{g}) \\
\end{array}$ & $\begin{array}{l}\text { Jumlah } \\
\text { Nodula } \\
\text { Efektif }\end{array}$ \\
\hline $\begin{array}{l}\text { Deteriorasi }(\mathrm{D}) \\
\mathrm{d}_{1}=\text { vigor baik } \\
\mathrm{d}_{2}=\text { vigor rendah }\end{array}$ & $\begin{array}{l}66,67 \text { a } \\
68,89 \text { a } \\
\end{array}$ & $\begin{array}{l}0,56 \text { a } \\
0,55 \text { a }\end{array}$ & $\begin{array}{c}12,44 \mathrm{a} \\
15,83 \mathrm{a}\end{array}$ \\
\hline $\begin{array}{l}\text { Pelapis Benih }(\mathrm{C}) \\
\mathrm{c}_{0}=\text { tanpa pelapis benih } \\
\mathrm{c}_{1}=\text { thiametoxam } \\
\mathrm{c}_{2}=\text { Rhizobium } \mathrm{sp}(\mathrm{R}) \\
\mathrm{c}_{3}=\text { Azotobacter sp }(\mathrm{A}) \\
\mathrm{c}_{4}=\mathrm{R}+\mathrm{A} \\
\mathrm{c}_{5}=\text { Trichoderma } \mathrm{sp}\end{array}$ & $\begin{array}{l}68,67 \text { a } \\
69,33 \text { a } \\
68,67 \text { a } \\
74,00 \text { a } \\
67,33 \text { a } \\
58,67 \text { a }\end{array}$ & $\begin{array}{l}0,57 \mathrm{a} \\
0,53 \mathrm{a} \\
0,54 \mathrm{a} \\
0,53 \mathrm{a} \\
0,59 \mathrm{a} \\
0,54 \mathrm{a}\end{array}$ & $\begin{array}{r}9,00 \mathrm{a} \\
11,00 \mathrm{a} \\
23,33 \mathrm{~b} \\
17,67 \mathrm{ab} \\
15,50 \mathrm{ab} \\
8,33 \mathrm{a}\end{array}$ \\
\hline $\begin{array}{l}\text { Keterangan : Angka y } \\
\text { sama pada kolom yan } \\
\text { berbeda nyata menuru } \\
\%\end{array}$ & $\begin{array}{l}\text { ditan } \\
\text { ama m }\end{array}$ & i hurt & $\begin{array}{l}\text { ng } \\
\text { tidak } \\
\text { nyata } 5\end{array}$ \\
\hline
\end{tabular}

Dosis bokashi yang semakin tinggi dapat menekan pertumbuhan kecambah atau bibit muda. Demikian pula apabila dosis pelapis benih kompos Trichoderma peningkatan dosis pengaruhnya tidak berbeda nyata dibandingkan dosis yang lebih rendah. Tinggi bibit 2 mst yang diberi 1 g kompos Trichoderma per 100 butir biji lebih tinggi dibandingkan dengan yang diberi thiametoksam, tetapi tidak berbeda nyata dengan kontrol dan pemberian kompos Trichoderma yang dosisnya lebih tinggi. Penambahan nutrisi dan populasi mikroba lebih tinggi menyebabkan tanaman tidak responsif. Pengaruh peningkatan dosis bokashi sampai $7,5 \mathrm{t} \mathrm{ha}^{-1}$ tidak berbeda nyata dengan control, bahkan apabila penambahan nutrisi yang berlebihan pada fase bibit dapat menekan pertumbuhan tanaman fase awal vegetatif.

Tabel 2. Pengaruh aplikasi pelapis benih Trichoderma sp dan bokashi terhadap vigor kecambah tanaman kedelai.

\begin{tabular}{|c|c|c|c|}
\hline Perlakuan & $\begin{array}{c}\text { Daya } \\
\text { Tumbuh } \\
(\%)\end{array}$ & $\begin{array}{c}\text { Bobot } \\
\text { Kering } \\
\text { Kecambah } \\
\text { (g) }\end{array}$ & $\begin{array}{c}\text { Tinggi } \\
\text { Tanaman } \\
2 \mathrm{mst} \\
(\mathrm{cm})\end{array}$ \\
\hline Tanpa Bokashi $\left(\mathrm{b}_{0}\right)$ & 73,87 a & 0,117 a & $13,86 \mathrm{~b}$ \\
\hline 7.5 tonHa-1 Bokashi $\left(b_{1}\right)$ & 70,40 a & 0,121 a & $13,61 \mathrm{~b}$ \\
\hline 15 tonHa-1 Bokashi $\left(b_{2}\right)$ & 72,80 a & 0,128 a & $12,65 \mathrm{a}$ \\
\hline$c v$ & 0,234 & 0,132 & 0,067 \\
\hline Tanpa Pelapis Benih $\left(\mathrm{c}_{0}\right)$ & 70,00 a & 0,126 a & $13,30 \mathrm{ab}$ \\
\hline Thiametoksam $\left(c_{1}\right)$ & 67,56 a & 0,112 a & 12,53 a \\
\hline $1 \mathrm{~g}$ Trico per 100 butir $\left(c_{2}\right.$ & 70,22 a & 0,117 a & $14,27 \mathrm{~b}$ \\
\hline $2 \mathrm{~g}$ Trico per 100 butir $\left(\mathrm{c}_{3}\right.$ & 77,33 a & 0,132 a & $13,39 \mathrm{ab}$ \\
\hline $3 \mathrm{~g}$ Trico per 100 butir $\left(c_{4}\right.$ & $70,67 \mathrm{a}$ & 0,132 a & $13,38 \mathrm{ab}$ \\
\hline$c v$ & 0,199 & 0,149 & 0,120 \\
\hline
\end{tabular}

Keterangan: nilai rata-rata pada kolom yang sama diikuti huruf yang sama menunjukkan tidak ada perbedaan yang nyata menurut uji BNT pada taraf uji $5 \%$

Komponen Hasil dan Hasil. Hal yang berbeda jika penambahan dosis kompos bokashi terhadap tumbuh reproduktif. Peningkatan dosis bokashi secara nyata dapat meningkatkan komponen hasil dan hasil tanaman, tetapi penggunaan pelapis benih tidak konsisten berpengaruh terhadap komponen hasil dan hasil biji per tanaman (Tabel 3 dan 4). Hal ini menunjukkan bahwa aplikasi pelapis benih pengaruhnya hanya sampai fase vegetatif awal.

Tabel 3. Komponen hasil, hasil, dan Indeks Panen Tanaman kedelai asal benih terdeteriorasi yang diberi berbagai pelapis benih.

\begin{tabular}{|c|c|c|c|c|c|c|}
\hline Perlakuan & $\begin{array}{l}\sum \text { polong isi }_{\text {tanaman }}^{-1} \\
\text { tant }\end{array}$ & $\begin{array}{l}\text { Mbiji } \\
\text { tanaman }^{-1}\end{array}$ & $\begin{array}{l}\text { Bobot } 100 \\
\text { butir }(\mathrm{g}) \\
\end{array}$ & $\begin{array}{l}\text { Bobotbiji } \\
\operatorname{tanaman}^{-1}(\mathrm{~g})\end{array}$ & $\begin{array}{l}\text { Bobot biji } \\
\mathrm{Ha}^{-1}(\mathrm{t})\end{array}$ & $\begin{array}{l}\text { Indeks } \\
\text { Panen }\end{array}$ \\
\hline \multicolumn{7}{|l|}{ Deteriorasi } \\
\hline $\mathrm{d} 1$ = vigor baik & 57,00 a & $134,27 \mathrm{a}$ & $13,47 \mathrm{a}$ & 18,87 a & 2,26 & $0,43 \mathrm{a}$ \\
\hline $\mathrm{d} 2=$ vigor rendah & $52,22 \mathrm{a}$ & 120,33 a & 13,18 a & 16,26 a & 1,95 & $0,38 \mathrm{a}$ \\
\hline \multicolumn{7}{|l|}{ Pelapis benih $(\mathrm{C})$} \\
\hline$c_{0}=$ tanpa pelapis & $57,16 \mathrm{ab}$ & $135,67 \mathrm{ab}$ & 13,82 a & $19,08 \mathrm{ab}$ & 2,28 & $0,43 \mathrm{a}$ \\
\hline$c_{1}=$ thiametoxam & $48,33 \mathrm{ab}$ & 108,67 a & 12,61 a & 14,53 a & 1,74 & $0,38 \mathrm{a}$ \\
\hline$c_{2}=$ Rhizobium sp & 47,16 a & 107,75 a & 13,28 a & 14,88 a & 1,78 & $0,40 \mathrm{a}$ \\
\hline$c_{3}=$ Azotobacter $\mathrm{sp}$ & $61,16 \mathrm{ab}$ & $140,67 \mathrm{ab}$ & 13,13 a & $18,82 \mathrm{ab}$ & 2,25 & $0,43 \mathrm{a}$ \\
\hline $\mathrm{C}_{4}=\mathrm{R}+\mathrm{A}$ & $50,67 \mathrm{ab}$ & $125,67 \mathrm{ab}$ & 13,51 a & $16,88 \mathrm{ab}$ & 2,02 & $0,39 \mathrm{a}$ \\
\hline $\mathrm{C}_{5}=$ Trichoderma & $63,17 \mathrm{~b}$ & $146,33 \mathrm{~b}$ & $13,60 \mathrm{a}$ & $21,19 \mathrm{~b}$ & 2,54 & $0,42 \mathrm{a}$ \\
\hline
\end{tabular}

Keterangan : Angka yang ditandai huruf yang sama pada kolom yang sama menunjukkan tidak berbeda nyata menurut uji BNT pada taraf nyata $5 \%$

${ }^{1}$ Data tidak diikuti notasi, karena tidak dianalisis secara statistik 
Tabel 4. Pengaruh aplikasi pelapis benih Trichoderma sp dan bokashi terhadap komponen hasil dan hasil tanaman kedelai.

\begin{tabular}{|c|c|c|c|c|c|c|c|}
\hline Perlakuan & $\begin{array}{l}\text { ¿Polong } \\
\text { Hampa } \\
\text { per } \\
\text { tanaman }\end{array}$ & $\begin{array}{l}\sum \text { Polong } \\
\text { Isi } \\
\text { tanaman }\end{array}$ & $\begin{array}{l}\sum \text { Biji }^{-1} \\
\text { tanaman }^{-1}\end{array}$ & $\begin{array}{l}\text { Bobot } 100 \\
\text { butir }(\mathrm{g})\end{array}$ & $\begin{array}{l}\text { Bobot Biji } \\
\text { tanaman }^{-1} \\
\text { (g) }\end{array}$ & $\begin{array}{l}\text { Hasil Ha-1 } \\
(\mathrm{t})\end{array}$ & $\begin{array}{l}\text { Indeks } \\
\text { Panen }\end{array}$ \\
\hline \multicolumn{8}{|l|}{ Bokashi } \\
\hline 0 ton & $3,707 \mathrm{a}$ & 47,967 a & 97,547 a & $15,12 \mathrm{a}$ & $14,429 \mathrm{a}$ & 1,734 & $0,422 \mathrm{a}$ \\
\hline 7.5 ton & 3,512 a & 52,033 a & 106,667 a & $16,07 \mathrm{a}$ & $16,647 \mathrm{~b}$ & 1,996 & $0,445 \mathrm{ab}$ \\
\hline 15 ton & $2,737 \mathrm{a}$ & 60,180 a & $121,967 \mathrm{~b}$ & $16,82 \mathrm{~b}$ & $19,830 \mathrm{c}$ & 2,378 & $0,474 \mathrm{~b}$ \\
\hline $\mathrm{CV}$ & 0,556 & 0,136 & 0,136 & 0,067 & 0,075 & & 0.079 \\
\hline \multicolumn{8}{|l|}{ Pelapis Benih } \\
\hline Tanpa pelapis & 2,967 a & 55,800 a & 110,056 a & $16,144 \mathrm{a}$ & 17,156 a & 2,056 & $0,429 \mathrm{a}$ \\
\hline Thiametoksam & 2,641 a & 54,056 a & 111,022 a & $15,978 \mathrm{a}$ & 17,209 a & 2.063 & $0,441 \mathrm{a}$ \\
\hline 1g kompTrico & 3,906 a & 52,944 a & 108,167 a & $16,333 a$ & $17,300 \mathrm{a}$ & 2.083 & $0,459 a$ \\
\hline $2 \mathrm{~g}$ komp Trico & 3,856 a & 54,167 a & 106,500 a & $15,656 \mathrm{a}$ & $16,306 \mathrm{a}$ & 1.957 & $0,445 \mathrm{a}$ \\
\hline $3 \mathrm{~g}$ kompTrico & 3,500 a & 50,000 a & 107,889 a & $15,900 \mathrm{a}$ & 16,822 a & 2.020 & $0,641 \mathrm{a}$ \\
\hline $\mathrm{CV}$ & 0,526 & 0,133 & 0,126 & 0,047 & 0,108 & & \\
\hline
\end{tabular}

Keterangan: nilai rata-rata pada kolom yang sama diikuti huruf yang sama menunjukkan tidak ada perbedaan yang nyata menurut uji BNT pada taraf uji $5 \%$

2 Data tidak dianalisis secara statistik

Semakin tinggi dosis bokashi yang diberikan dapat meningkatkan jumlah biji, ukuran biji, bobot biji per tanaman, dan indeks panen. Meskipun pengaruh peningkatan dosis bokashi terhadap jumlah polong isi tidak nyata, tetapi ada kecenderungan mampu mening-katkan polong isi. Bokashi yang diperkaya dengan EM merupakan kompos yang mampu menyediakan unsur hara secara terus menerus (slow release) sampai akhir fase reproduktif (Sumadi dkk., 2013; Hua dan Qi, 2013). Adanya komunitas mikroorganisme di daerah rhizosphere dapat membantu ketersediaan hara bagi tanaman (Marschner, 2008).

Hasil biji per tanaman yang tertinggi diperoleh pada tanaman yang diberi dosis bokashi $15 \mathrm{t}$ ha $^{-1}$. Apabila dikonversikan ke hektar, maka pemberian dosis bokashi tertinggi mampu menghasilkan biji sebesar 2,378 $\mathrm{t} \mathrm{ha}^{-1}$ atau $27,8 \%$ lebih tinggi dibandingkan dengan yang tidak diberi kompos bokashi. Hal ini berarti mencapai potensi hasil kultivar Anjasmoro (Suhartina, 2005).

\section{Kesimpulan dan Saran}

Berdasarkan uraian sebelumnya dapat disimpulkan bahwa tidak ada pengaruh interaksi antara dosis kompos Trichoderma dengan dosis bokashi terhadap semua parameter yang diamati. Tanaman asal benih yang dilapisi Trichoderma dosis rendah mampu menghasilkan bobot biji yang tidak berbeda nyata dengan tanaman asal benih yang diberi Trichoderma dosis yang lebih tinggi maupun penggunaan pelapis benih berupa insektisida, yaitu 17,350 g per tanaman atau 2,083 $\mathrm{t} \mathrm{ha}^{-1}$. Pemberian bokashi secara nyata meningkatkan jumlah biji, ukuran biji dan hasil biji per tanaman. Tanaman yang diberi bokashi 15 ton ha-1 mampu menghasilkan 19,830 g biji per tanaman setara 2,378 t Ha-1 atau 27,08 \% lebih tinggi dibandingkan kontrol.

Berdasarkan kesimpulan dapat disarankan untuk memperoleh informasi yang lebih komprehensif perlu mengkaji lebih lanjut tentang peranan kompos Trichoderma spp. dan bokashi dalam peningkatan produktivitas berbagai varietas unggul tanaman kedelai asal benih terdeteriorasi langsung di lahan kering maupun sawah yang kesuburannya marginal.

\section{Ucapan Terima Kasih}

Pada kesempatan ini kami ucapkan terima kasih kepada Direktorat Perguruan Tinggi yang telah mendanai penelitian ini serta pihak-pihak yang membantu memperlancar terselenggaranya selama pelaksanaan penelitian di lapangan. 


\section{Daftar Pustaka}

Adisarwanto, T. dan R. Wudianto.1999. Meningkatkan hasil panen Kedele di lahan Sawah, Lahan Kering dan Pasang Surut. Penebar Swadaya. Jakarta.

Agustiansyah, S. Ilyas, Sudarsono dan M. Machmud, 2010. Pengaruh perlakuan Benih Secara Hayati pada Benih Padi Terinfeksi Xanthomonas oryzae terhadap Mutu benih dan Pertumbuhan Bibit. J. Agron. Indonesia 38 (3) : 185-191

Copeland, L.O., and M.B McDonald. 2004. Principles of Seed Science and Technology. Burgess Publ. Co. Minneapolis, Minnesota.

Ginting, E., S. S. Antarlina, dan S. Widowati. 2009. Varietas unggul kedelai untuk bahan baku industry pangan. Jurnal Litbang Pertanian, 28(3): 79 -87

Harman, G.E., C.R. Howell, A. Viterbo, I. Chert and M. Lorito. 2004. Trichoderma species opportunistic, avirulent plant symbions. Nature Reviews Microbiology 2 : 43-56.

Harman, G.E. 2006. Overview of Mechanisms and Uses of Trichoderma spp. Symposium The Nature and Application of Biocontrol Microbes II: Trichoderma spp. Phytopathology. Vol. 96, No. 2 : 190-194

Hua, C., and Y.Qi . 2013. Long-term effective microorganisms application promote growth and increase yields and nutrition of wheat in China Europ. J. Agronomy 46 (2013) 63-67.

Ilyas, S. 2012. Ilmu dan Teknologi Benih.Teori dan hasil-hasil Penelitian. PT.Penerbit IPB Press. Bogor

Marschner, P. 2008. The role of rhizosphere microorganism in relation to $P$ uptake by plant.In P.J. White and J.P. Hammond (Eds.). The Ecophysiology of Plant Phosporus Interaction. Springer. 165 - 176
Marwoto, S. Hardiningsih dan T. Abdulah. 2006. Hama, Penyakit, dan Masalah Hara pada Tanaman Kedelai.Pusat Peneltian dan Pengembangan Tanaman Pangan. Bogor.

Prihastuti dan Sudaryono, 2008.Evaluasi masukan agen hayati pada uji paket teknologi budidaya kedele di lahan kering masam Lampung tengah. Pros. Sem. Inovasi Teknologi Kacang-kacangan dan Umbi-umbian Mendukung Kemandirian Pangan dan Kecukupan Energi. Balitbangtan. 353-362.

Rahman, F.H., Sumadi, A. Nuraini. 2014. Pengaruh pupuk $\mathrm{P}$ dan bokashi terhadap pertumbuhan, komponen hasil, dan kualitas hasil benih kedelai. Agric. Sci. J. Vol. I (4) : 254-261

Rodelas, B., J. G. Lopez, M.V. Martinez-Toledo, C. Pozo, and V. Salmeron. 1999. Influence of Rhizobium/Azotobacter and Rhizobium/Azospirilium combined inoculation on mineral composition of faba bean (Vicia faba). Biol.Fertil.Soil (29): 165-169

Suhartina. 2005. Deskripsi Varietas Unggul Kacang-kacangan dan Umbi-umbian. Balitkabi, Malang.

Sumadi, A.Nuraini, C. Sekaryuniarti. 2011. Pengaruh Seed Coating dengan Insek-tisida Berbahan Aktif Thiametoksam terhadap Viabilitas, Vigor Benih, dan Bibit serta dampaknya terhadap Pertumbuhan dan Hasil Tanaman Kedelai. Laporan Penelitian. Faperta Unpad (Tidak dipublikasi).

Sumadi, R. Devnita, dan B. Riznati. 2013. Pengaruh Seed coating dengan Thiametoxam dan Bokashi terhadap pertumbuhan dan hasil benih kedele. Laporan Penelitian. Prog. Studi Agroteknologi. Faperta Unpad (Tidak dipublikasi).

Sumadi. 2015. Prospek pelapis benih dalam meningkatkan produktivitas kedelai. Prosiding Seminar Hasil Penelitian Tanaman Aneka Kacang dan Umbi 2014. Halaman 343- 350 